\title{
Pendampingan Tata Kelola Badan Usaha Milik Desa (BUMDes) Katon Margo Sembada Berbasis Teknologi Informasi Dan Komunikasi
}

\section{Assistance in the Governance of Village Owned Enterprises Katon Margo Sembada Based on Information and Communication Technology}

\author{
Sakir*1, Laras Astuti ${ }^{2}$, Muhammad Muttaqien ${ }^{3}$, Dyah Mutiarin $^{4}$ \\ ${ }^{1,2.3,4}$ Universitas Muhammadiyah Yogyakarta, Bantul, Indonesia \\ 1․mas.sakir@,fisipol.umy.ac.id, ${ }^{2}$ larasastuti76@yahoo.co.id \\ *Penulis Korespondensi
}

Riwayat Artikel: Dikirim 24 Juni 2021; Diterima 6 Agustus 2021; Diterbitkan 30 November 2021

\begin{abstract}
Abstrak
BUMDes Katon Margo Sembada menjadi salah satu BUMDES yang terdampak selama pandemi covid - 19. Dampak tersebut dapat dilihat dari menurunnya pendapatan sebesar 30\%. Hal tersebut terjadi karena selama ini BUMDES Katon Margo Sembada, masih menggunakan metode konvensional dalam pemasarannya. Tidak ada website maupun media social terkait unit usaha BUMDES Katon Margo Sembada menjadikan BUMDES ini tidak berkembang dan tidak dikenal oleh banyak orang. Selain itu BUMDES Katon Margo Sembada juga kekurangan sumber daya manusia yang mampu mengelola BUMDES dengan baik melalui marketplace dan digital marketing. Lebih lanjut, pengabdian masyarakat ini bertujuan untuk melakukan pendampingan terhadap BUMDES Katon Margo Sembada berbasis teknologi, informasi dan komunikasi agar unit usaha yang dikelola dapat dikenal oleh masyarakat luas. Melalui metode pendekatan pemberdayaan masyarakat, pengabdian ini di harapkan dapat mengubah keberadaan masyarakat menjadi lebih mandiri, produktif dan sejahtera. Berdasarkan hasil penilaian awal (initial assessment) permasalahan, tim pengabdi sudah melakukan pendampingan dalam pembuatan website, media sosial, pendampingan dan pelatihan tata kelola media, digital marketing dan marketplace. Selain itu tim pengabdi juga melakukan inisiasi dengan menjalin kerjasama yang startegis antara BUMDES Katon Margo Sembada dengan Laboratorium Ilmu Pemerintahan Universitas Muhammadiyah Yogyakarta dalam pelaksanaan Pengelolaan dan Pendampingan Berbasis Teknologi Informasi dan Komunikasi.
\end{abstract}

Kata kunci: BUMDes, Digital Marketing, Pemberdayaan.

\begin{abstract}
The BUMDes of Katon Margo Sembada is one of the BUMDes affected during the covid-19 pandemic. This impact can be seen from the decrease in income by 30\%. This happens because so far BUMDES Katon Margo Sembada, still uses conventional methods in marketing. There is no website or social media related to the BUMDES business unit of Katon Margo Sembada, making this BUMDES undeveloped and unknown to many people. In addition, BUMDES Katon Margo Sembada also lacks buman resources who can manage BUMDES well through the marketplace and digital marketing. Furthermore, this community service aims to aid BUMDES Katon Margo Sembada based on technology, information, and communication so that the managed business units can be known by the wider community. Through the community empowerment approach, this service is expected to change the existence of the community to be more independent, productive, and prosperous. Based on the results of the initial assessment of the problem, the team has aided in website creation, social media, mentoring and training in media, digital marketing, and marketplace. In addition, the team also initiated by establishing strategic collaboration between BUMDES Katon Margo Sembada and the Government Science Laboratory, University of Mubammadiyah Yogyakarta in the implementation of Information and Communication Technology-Based Management and Assistance.
\end{abstract}

Keywords: BUMDes, Digital Marketing, Empowerment.

\section{PENDAHULUAN}

Bencana Pandemi COVID-19 di Indonesia yang belum dapat diatasi dengan baik, berdampak pada keberlangsungan kegiatan perekonomian desa yang dilakukan oleh BUMDes. Menurut Menteri Desa, 
Pembangunan Daerah Tertinggal dan Transmigrasi bahwa dari 74.953 desa, telah terbentuk sekitar 51.000 BUMDes di Indonesia. Sebelum pandemi COVID-19 terjadi, sekitar 37.000 di antaranya telah menjalankan usaha atau telah melakukan transaksi ekonomi. Namun, saat pandemi COVID-19 tinggal 10.026 BUMDes yang masih melakukan transaksi ekonomi (ANTARA, 2020). Hal ini menunjukkan bahwa banyak BUMDes yang terkena dampak dari adanya bencana Pandemi COVID-19 sehingga kegiatan perekonomian berhenti.

Berdasarkan Peraturan Menteri Desa, Pembangunan Daerah Tertinggal dan Transmigrasi Nomor 4 Tahun 2015 Tentang Pendirian, Pengurusan dan Pengelolaan, dan Pembubaran Badan Usaha Milik Desa (2015), bahwa BUMDes, adalah badan usaha yang seluruh atau sebagian besar modalnya dimiliki oleh Desa melalui penyertaan secara langsung yang berasal dari kekayaan Desa yang dipisahkan guna mengelola aset, jasa pelayanan, dan usaha lainnya untuk sebesar-besarnya kesejahteraan masyarakat Desa. Pendirian BUMDes bertujuan: meningkatkan perekonomian Desa; mengoptimalkan aset Desa agar bermanfaat untuk kesejahteraan Desa; meningkatkan usaha masyarakat dalam pengelolaan potensi ekonomi Desa; mengembangkan rencana kerja sama usaha antar desa dan/atau dengan pihak ketiga; menciptakan peluang dan jaringan pasar yang mendukung kebutuhan layanan umum warga; membuka lapangan kerja; meningkatkan kesejahteraan masyarakat melalui perbaikan pelayanan umum, pertumbuhan dan pemerataan ekonomi Desa; dan meningkatkan pendapatan masyarakat Desa dan Pendapatan Asli Desa.

Desa Margokaton adalah desa yang terletak di Kecamatan Seyegan Kabupaten Sleman Provinsi Daerah Istimewa Yogyakarta. Desa Margokaton terdiri dari 13 pedukuhan terletak di sebelah barat Kabupaten Sleman. Desa Margokaton memiliki BUMDes yang diresmikan pada tanggal 30 Juli 2017 dengan nama "BUMDes Katon Margo Sembada" didirikan berdasarkan UU Nomor 6 Tahun 2014 tentang Desa (2014) dan juga dengan adanya Perda Kabupaten Sleman Nomor 3 Tahun 2013 tentang tata cara pembentukan BUMDes (2013), sebagai wadah bagi masyarakat Desa Margokaton untuk menjembatani seluruh UMKM dan potensipotensi yang berada di Desa Margokaton.

BUMDes Katon Margo Sembada memiliki 3 unit usaha yaitu produksi, jasa, dan retail. Produksi bergerak dalam bidang pembuatan batako, jasa bergerak dalam bidang galeri batik dan retail bergerak dalam bidang Desa Mart yaitu minimarket. Salah satu misi dari BUMDes Katon Margo Sembada adalah "Mengembangkan Jaringan Kerja sama Ekonomi dengan BUMDes yang lain maupun berbagai Pihak". Maka dari itu, perlu dilakukan kerja sama dengan pihak yang lebih luas sehingga dibutuhkannya Media penghubung antara BUMDes Katon Margo Sembada dengan pihak-pihak yang lain.

Gambar 1:

Unit usaha retail milik BUMDes Katon Margo Sembada berupa minimarket

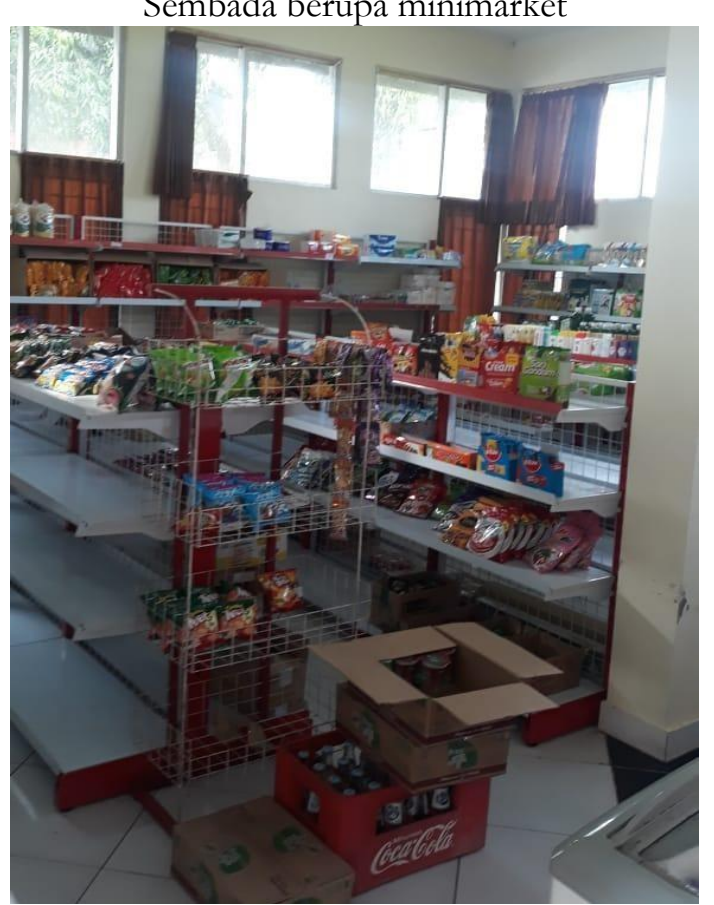

Sumber: Tim Dokumentasi KKN IT 211 
Gambar 2:

Unit usaha jasa milik BUMDes Katon Margo Sembada berupa galeri batik

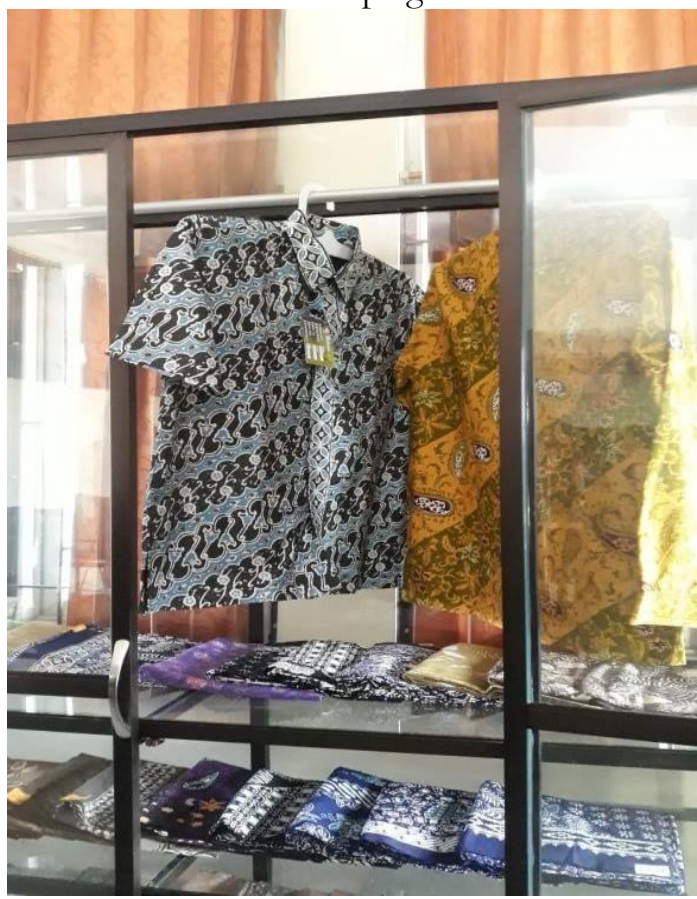

Sumber: Tim Dokumentasi KKN IT 211

Gambar 3:

Unit usaha produksi milik BUMDes Katon Margo Sembada berupa pembuatan batako

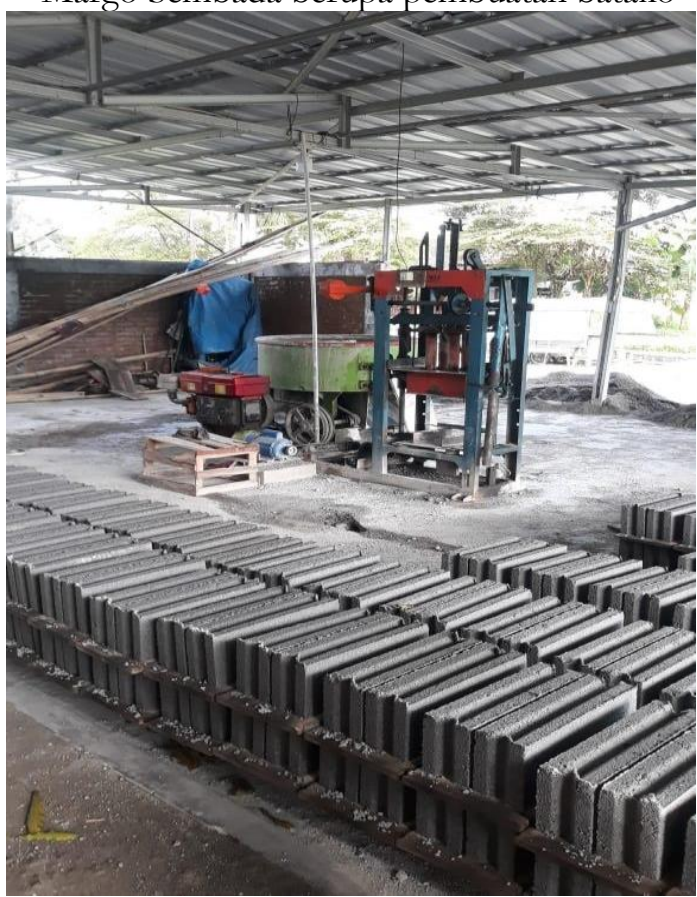

Sumber: Tim Dokumentasi KKN IT 211
Permasalahan yang dihadapi BUMDes Katon Margo Sembada di masa Pandemi COVID-19 di antaranya adalah penurunan pendapatan sebesar $30 \%$, dan pemasaran produk yang masih menggunakan metode konvensional. Pembeli yang ingin melihat barang harus berkunjung dulu ke BUMDes Katon Margo Sembada sehingga tidak praktis dalam pemasarannya. Tidak adanya website dan media sosial membuat kurangnya informasi mengenai BUMDes maupun barang-barang yang akan dipasarkan. Tidak adanya website dan media sosial disebabkan pula karena kekurangan sumber daya manusia dalam mengelolanya sehingga banyak orang yang tidak mengerti tentang produk-produk yang dipasarkan. Selain itu, sumber daya manusianya juga belum memahami terkait digital marketing dan marketplace.

Pengabdian yang berkaitan dengan pendampingan badan usaha milik desa tentu bukan kali pertama dilakukan di Indonesia. Meskipun demikian, pengabdian yang dilakukan oleh tim pengabdi saat ini berbeda dengan pengabdian yang sebelumnya pernah dilakukan. Seperti pengabdian yang dilakukan oleh Lucy Sri Musmini dkk. (Lucy, 2020) yang berjudul "Pemberdayaan BUMDes Giri Amertha Desa Sambangan Melalui Pelatihan dan Pendampingan Sistem Informasi Akuntansi." Pengabdian tersebut berfokus pada pendampingan pengembangan sistem informasi akuntansi yang telah di rancang dengan meningkatkan tata Kelola BUMDes terutama yang berkaitan dengan proses pencatatan dan pelaporan keuangan menggunakan aplikasi yang telah diajarkan.

Senada yang dilakukan oleh Lucy, pengabdian yang dilakukan oleh Handajani dkk. (Handajani et al., 2021) dengan judul Pendampingan Perintisan Usaha BUMDes untuk Pemberdayaan Ekonomi Masyarakat Desa Peteluan Indah" juga berfokus pada peningkatan pemberdayaan ekonomi masyarakat desa dengan membuat potensi unggulan desa dan merumuskan prioritas 
rencana bisnis BUMDes.

Pengabdian selanjutnya dilakukan oleh Karinda dkk. (2020) berjudul "Tata Kelola Badan Usaha Milik Desa (BUMDes)". Pengabdian tersebut dilakukan di Desa Kiawa Satu Utara dan Desa Kiawa Dua Induk Kecamatan Kawangkoan Utara Kabupaten Minahasa dan berfokus pada nilai kooperatif, partisipatif, transparansi dan akuntabel dalam mengelola BUMDes.

Senada yang dilakukan oleh Amrina Rosyada dkk. (2019) yang berjudul "Pendampingan Pembentukan Badan Usaha Milik Desa (BUMDes) Desa Kendalasem Wedung Demak" berfokus pada tahapan-tahapan yang harus dilakukan dalam pembentukan BUMDes seperti pendampingan penentuan nama BUMDes dan pemetaan desa, pendampingan pembahasan Perdes, sosialisasi tahapan dan pendampingan dalam musyawarah desa.

Pengabdian selanjutnya dilakukan oleh Badri (Badri, 2016) yang berjudul "Pembangunan Pedesaan Berbasis Teknologi Informasi dan Komunikasi (Studi Pada Gerakan Desa Membangun)" yang berfokus pada pengembangan membangun website desa, pengembangan aplikasi mitra, pengembangan aplikasi lumbung desa, dan membangun interkoneksi desa-desa yang mendukung pengambilan inisiatif pembangunan.

Senada yang dilakukan oleh Hartoyo dkk. (2016) yang berjudul Citalinuabdi : Upaya Membangun Sistem Informasi Desa Yang Bermakna. Pengabdian tersebut juga berfokus pada upaya pengelolaan dan pengembangan SID sebagai salah satu amanat UU Desa sudah mulai dirintis oleh warga. Namun demikian, SID yang sudah ada perlu dikembangkan dengan strategi pendampingan dan pelatihan terkait pengembangan dan pemanfaatan media massa daring lebih lanjut.

Beragam contoh pengabdian di atas meski ada beberapa yang sama, namun dari segi fokus program kerja jelas memiliki perbedaan dengan pengabdian ini. Karena pengabdian yang dilakukan oleh tim pengabdi berfokus pada hasil observasi tim pengabdi ke BUMDes Katon Margo Sembada. Adapun hasil observasi ditemukan sebagai berikut:

\section{a. Pemasaran menggunakan metode} konvensional

BUMDes Katon Margo Sembada masih menggunakan metode pemasaran konvensional, sehingga para pelanggan harus mendatangi BUMDes Katon Margo Sembada secara langsung untuk mengetahui dan membeli produk.

\section{b. Tidak memiliki website dan media sosial}

BUMDes Katon Margo Sembaga tidak memiliki website dan sosial media, sehingga menyebabkan kurang dikenalnya BUMDes itu sendiri di masyarakat yang lebih luas. Selain itu, kurangnya SDM yang memahami dan mengelola website dan media sosial.

\section{c. Minimnya Kerja sama yang dilakukan oleh BUMDes}

BUMDes Katon Margo Sembada belum memiliki kerja sama yang mendukung kegiatan perekonomian desa. Hal ini disebabkan karena keterbatasan SDM yang dapat menginisiasi kerja sama dengan pihak lain.

Berdasarkan hal tersebut, orisinalitas pengabdian yang akan dilakukan akan berfokus pada:

a. Memasarkan unit usaha yang terdapat dalam BUMDes Katon Margo Sembada secara daring

b. Membuat website dan sosial media sebagai sarana pemasaran digital dan marketplace.

c. Menjalin kerja sama dengan mitra terkait yang dapat mendukung kegiatan perekonomian desa..

\section{METODE}

Korten (2002) menyatakan konsep pembangunan yang berpusat pada rakyat (People Centred Development) memandang inisiatif rakyat sebagai sumber daya pembangunan yang paling utama dan 
memandang kesejahteraan material dan spiritual sebagai tujuan yang ingin dicapai. Upaya untuk melaksanakan pembangunan yang berpusat pada rakyat dilakukan melalui pemberdayaan. Pemberdayaan masyarakat pada prinsipnya merupakan upaya untuk mengubah keberadaan masyarakat menjadi lebih mandiri, produktif dan sejahtera.

Proses pemberdayaan masyarakat bertujuan untuk mewujudkan masyarakat yang mampu mengidentifikasi dan menganalisis permasalahannya sendiri, memfasilitasi masyarakat agar mampu merumuskan beberapa alternatif pemecahan masalahnya, dan mendorong masyarakat agar mampu menggali potensi sekaligus mengembangkannya. Akan tetapi, semua itu dapat dilakukan dengan mudah, tepat, efektif, dan efisien.

Berikut tahapan pelaksanaan program kegiatan sebagai berikut:

\section{a. Penilaian awal (initial assessment)} Permasalahan

Akan dilakukan FGD daring untuk mengidentifikasi permasalahan lebih detail mengenai apa saja kekurangan, potensi, dan hambatan di BUMDes Katon Margo Sembada. FGD ini akan dilaksanakan dengan Pemerintah Desa, Pengurus BUMDes, UMKM dan Organisasi sosial.

b. Pembuatan Website dan Media Sosial BUMDes

Akan dilakukan bersama dengan pengurus BUMDes. Membuat format/desain website dan media sosial sesuai apa yang disepakati. Konsep Website dan media sosial akan disesuaikan dengan kebutuhan BUMDes Katon Margo Sembada.

c. Pendampingan dan Pelatihan Tata Kelola Website dan Media Sosial

Workshop untuk mengelola Website dan Media Sosial. Memberikan pendampingan kepada pengelola $W$ ebsite dan Media Sosial terkait tata cara mengelola profil BUMDes dan promosi produk yang menarik.

\section{d. Pelatihan Digital Marketing}

Pelatihan ini bertujuan untuk memberikan pemahaman digital marketing dan marketplace kepada pengurus BUMDes Katon Margo Sembada, Pemerintah Desa, UMKM dan Karang taruna.

e. Penjajakan Kerja sama dengan Mitra Strategis BUMDes

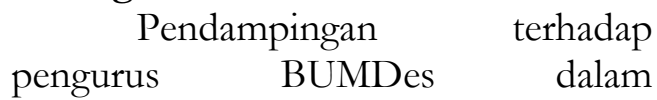
meningkatkan kerja sama dengan mitra strategis untuk meningkatkan kegiatan perekonomian desa. Hal ini bertujuan untuk meningkatkan jejaring BUMDes, sehingga dapat mengembangkan bisnis yang ada di BUMDes.

\section{HASIL DAN PEMBAHASAN}

Berikut adalah implementasi proses pengabdian yang telah dilakukan berdasarkan program kerja yang telah disusun, yaitu:

a. Penilaian Awal (Initial Assessment) permasalahan

Program ini bertujuan untuk mengidentifikasi permasalahan yang lebih detail mengenai apa saja kekurangan, potensi, dan hambatan yang berada di BUMDes Katon Margo Sembada. Dengan adanya kegiatan ini maka dapat menemukan solusi untuk menyelesaikan permasalahan yang ada secara bersama. Kegiatan FGD ini dilaksanakan pada tanggal 21 Januari 2021 dilaksanakan di Aula Kantor Kelurahan Margokaton, dengan dihadiri oleh pihak pengurus BUMDes Katon Margo Sembada, UMKM, dan Organisasi Sosial Karang Taruna Muda Katon Sembada. Dalam FGD tersebut BUMDes Katon Margo Sembada, Karang taruna Muda Katon Sembada dan pelaku UMKM mengharapkan agar dapat mengembangkan sektor penjualan melalui marketplace dan media sosial sebagai sarana penjualan maupun promosi. Sehingga diharapkan mampu 
memberikan dampak positif terkait dengan apa saja yang menjadi potensi di Kelurahan Margokaton.

Gambar 4:

Pelaksanaan FGD di Aula Kelurahan Margokaton

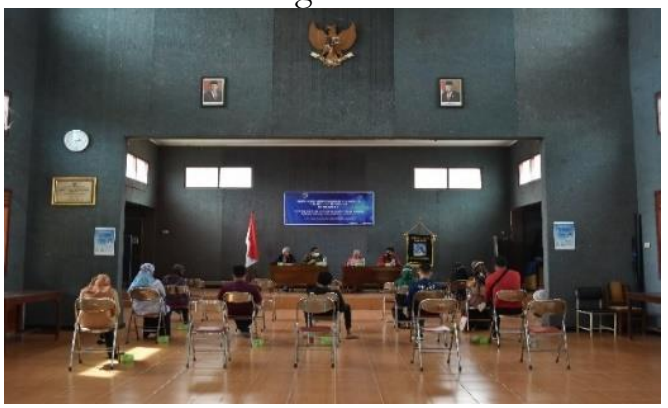

Sumber: Tim Dokumentasi KKN IT 211

\section{b. Pembuatan Website dan Media Sosial BUMDes}

Program ini bertujuan untuk membuat format ataupun desain website dan media sosial sesuai dengan yang telah disepakati Bersama. Konsep website dan media sosial akan disesuaikan dengan kebutuhan BUMDes Katon Margo Sembada serta organisasi Karang Taruna Muda Katon Sembada.

Kegiatan ini dilakukan berawal dari pembuatan konten Instagram seperti membuat desain-desain seperti feed, story, highlight dan template feed Instagram bagi masing-masing mitra, serta pembaruan media sosial Instagram yang sudah ada seperti pembaruan pada profil media sosial dari masing-masing mitra misal seperti menambahkan alamat serta mengubah profil Instagram ke akun bisnis. Kegiatan ini ditujukan kepada pengelola BUMDes Katon Margo Sembada dan juga Karang Taruna Muda Katon Sembada.
Gambar 5:

Pendampingan Pengelolaan Media Sosial Mitra BUMDes

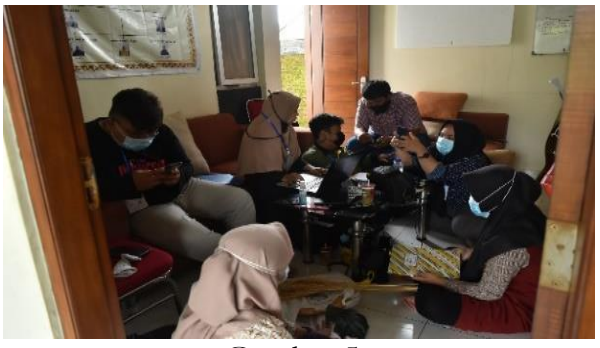

Gambar $5 a$

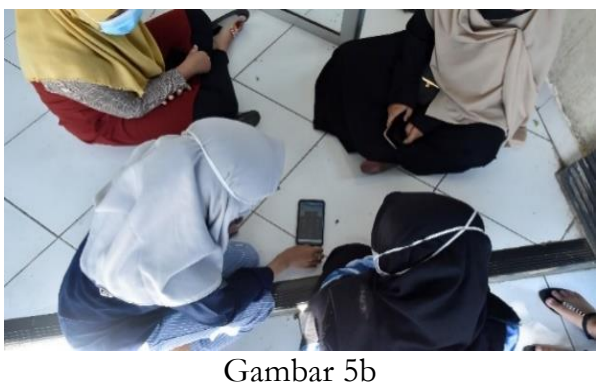

Sumber: Tim Dokumentasi KKN IT 211

c. Pendampingan dan Pelatihan Tata Kelola Website dan Media Sosial.

Program ini bertujuan untuk melakukan pendampingan tentang Tata Kelola Website dan Media Sosial. Untuk mengetahui bagaimana membuat format atau desain website dan media sosial secara menarik dan memberikan pendampingan untuk tata cara mengelola profil BUMDes dan dapat digunakan sebagai promosi produk yang secara menarik sehingga dapat menarik minat konsumen. Kegiatan ini juga mengadakan Workshop dengan judul "Pelatihan Tata Kelola Website dan Media Sosial" kegiatan ini dilaksanakan pada tanggal 04 Februari 2021 bertempat di Aula Kantor Desa Margokaton. Pada workshop ini menghadirkan tiga pemateri dengan materi yang beda-beda. 
Pemateri pertama menjelaskan tentang jurus membuat konten media sosial dan website. Pemateri kedua menjelaskan tentang desain grafis untuk promosi dan branding, dan pemateri ketiga menjelaskan tentang video promosi cukup menggunakan ponsel.

Selanjutnya perwakilan dari masing-masing mitra akan diberikan pendampingan pelatihan secara langsung oleh tiap pemateri, baik itu bagaimana cara mengelola website dan media sosial serta praktik membuat video dengan aplikasi yang cukup dengan menggunakan ponsel.

Gambar 6:

Workshop Pengelolaan Media Sosial dan

Website di Aula Kalurahan Margokaton

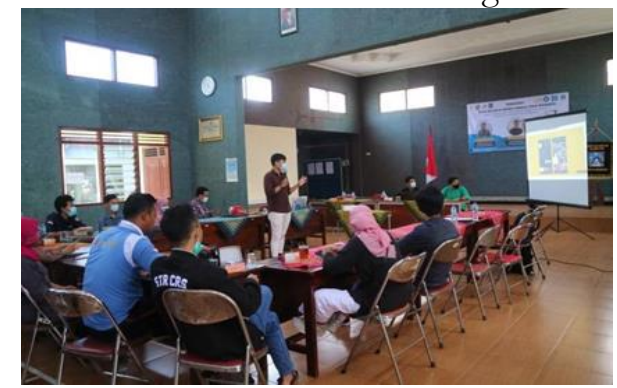

Sumber: Tim Dokumentasi KKN IT 211

\section{d. Pelatihan Digital Marketing}

Program ini bertujuan untuk melakukan pelatihan bersama dengan mengagendakan pertemuan dengan metode Workshop bertema "Pelatihan Digital Marketing" dengan judul "Fundamental Digital Marketing". Kegiatan ini dilaksanakan pada tanggal 07 Februari 2021 bertempat di Pendopo Desa Wisata Gamplong Sumber Rahayu, menghadirkan pemateri untuk berdiskusi dalam satu forum membahas pemanfaatan dan bagaimana cara untuk melaksanakannya.

Pelatihan ini juga bertujuan untuk memberikan pemahaman digital marketing dan marketplace untuk memasarkan produk yang awalnya penjualan dengan metode konvensional nantinya dapat bertransformasi kepada digital marketing dengan memanfaatkan media pemasaran daring.

Kegiatan ini ditujukan kepada pengurus BUMDes Katon Margo Sembada, Pemerintah Desa, UMKM dan Karang Taruna. Dengan adanya Pelatihan Digital Marketing ini diharapkan mampu mengikuti perkembangan zaman sehingga dapat meningkatkan penjualan secara digital.

Gambar 7:

Pelatihan Digital Marketing di Pendopo Gamplong Kelurahan Sumberrahayu
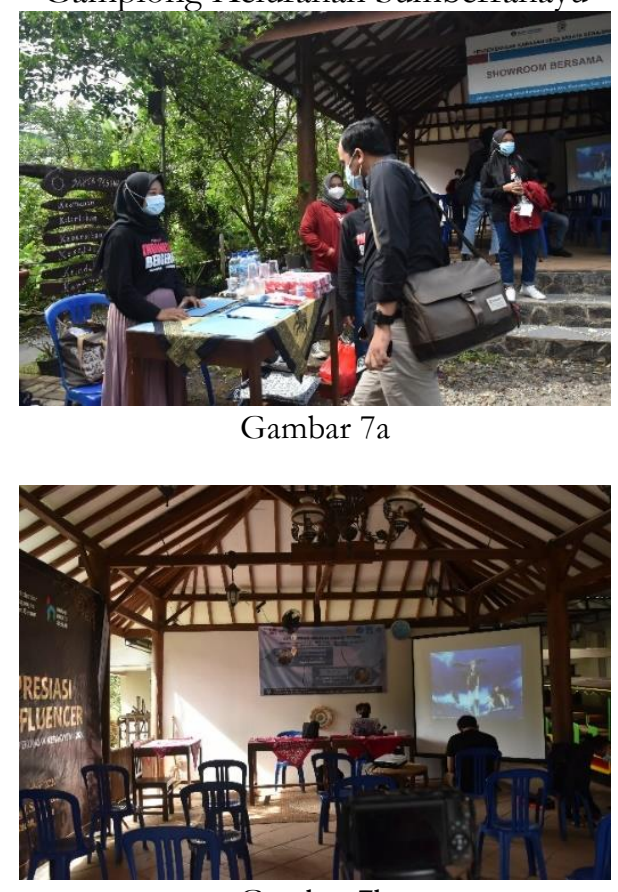

Gambar 7b

Sumber: Tim Dokumentasi KKN IT 211

e. Penjajakan Kerja Sama dengan Mitra Strategis BUMDes BUMDes Katon Margo Sembada melalui Kelurahan Margokaton bekerja sama dengan Laboratorium Ilmu Pemerintahan Universitas Muhammadiyah Yogyakarta dalam pelaksanaan Pengelolaan dan Pendampingan Berbasis Teknologi Informasi dan Komunikasi. Diharapkan nantinya kerja sama dengan Lab. IP UMY ini akan membawa perubahan ataupun peningkatan di BUMDes Katon Margo Sembada dan Kelurahan 
Margo Katon khususnya dalam sektor Teknologi Informasi dan Komunikasi.

Gambar 8:

Pemerintah Kelurahan Margokaton dan Direktur BUMDes Katon Margo Sembada berkunjung ke Laboratorium Ilmu

Pemerintahan Universitas Muhammadiyah Yogyakarta

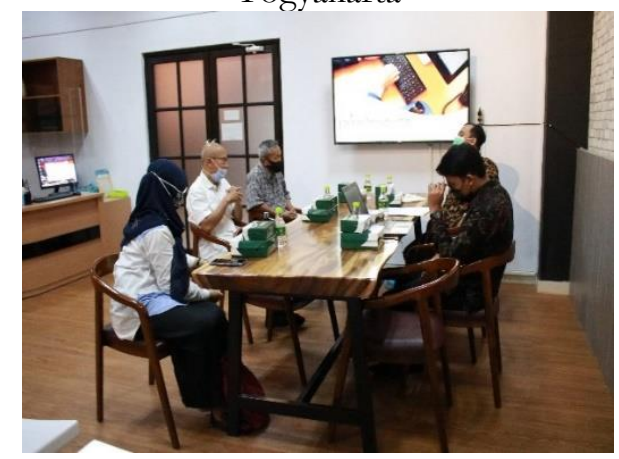

Sumber: Tim Dokumentasi Laboratorium Ilmu Pemerintahan Universitas Muhammadiyah Yogyakarta

\section{f. Foto Produk BUMDes}

Foto produk ini bertujuan untuk membantu dalam mengembangkan fotonya agar lebih menarik sehingga dapat menarik pihak konsumen. Kegiatan ini menggunakan properti sebagai media pendukung foto produk agar terlihat menarik dan media yang dilakukan dapat berupa dengan menggunakan kamera bahkan ponsel. Hasil foto produk yang telah jadi selanjutnya diunggah di akun Instagram atau Facebook marketplace pihak mitra.

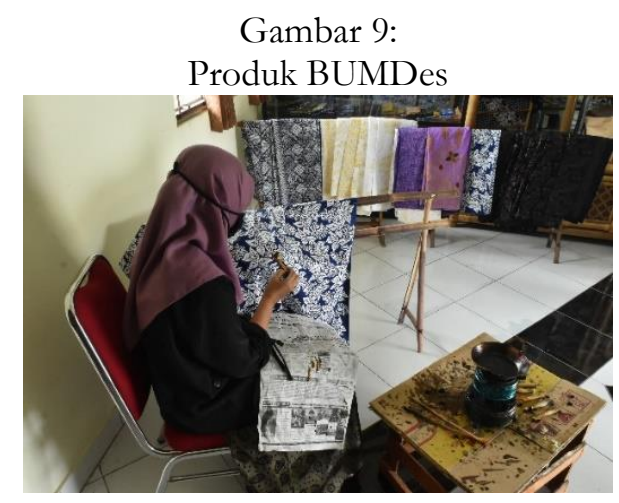

Gambar 9a

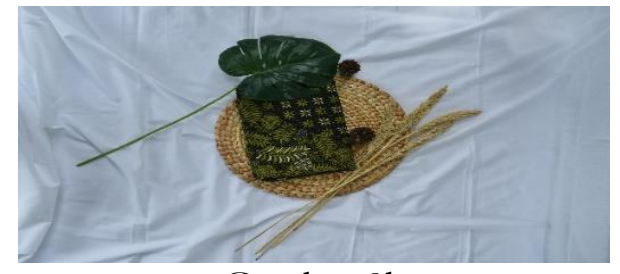

Gambar 9b

Sumber: Tim Dokumentasi KKN IT 211

\section{g. Pembuatan Banner BUMDes}

Kegiatan pembuatan banner ini bertujuan untuk memberikan identitas pada BUMDes Katon Margo Sembada. Banner ini diletakan pada 3 titik tempat yaitu pertama terletak pada produksi batako yang berisikan mengenai seluruh unit usaha BUMDes Katon Margo Sembada kedua, terletak pada Desa Mart dan yang ketiga banner tersebut diletakkan pada galeri hasil produksi batik BUMDes Katon Margo Sembada. Dengan pemberian banner ini nantinya dapat sebagai media promosi ataupun iklan yang dapat menarik perhatian bagi banyak orang yang melihatnya.

Gambar 10:

Pemasangan Banner BUMDes
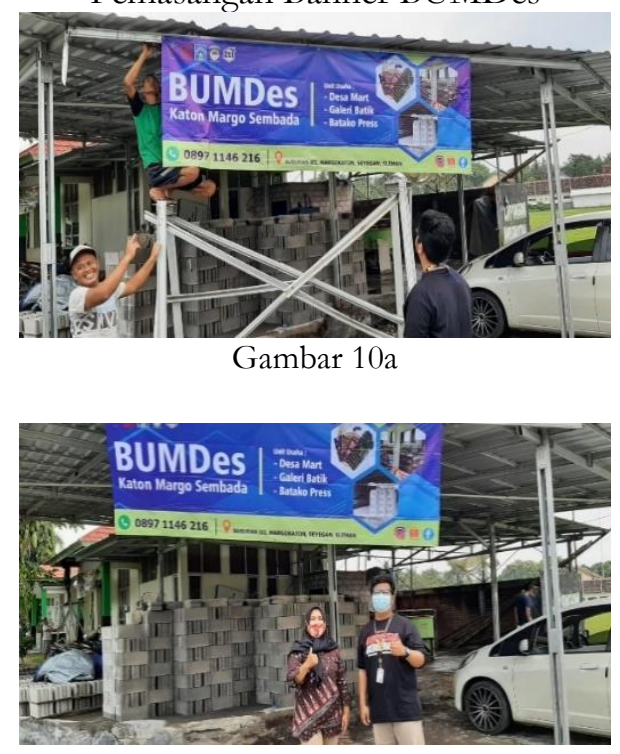

Gambar 10b

Sumber: Tim Dokumentasi KKN IT 211 


\section{KESIMPULAN}

BUMDes Katon Margo Sembada memiliki 3 unit usaha yaitu produksi, jasa, dan retail. Produksi bergerak dalam bidang pembuatan batako, jasa bergerak dalam bidang galeri batik dan retail bergerak dalam bidang Desa Mart yaitu minimarket. Salah satu misi dari BUMDes Katon Margo Sembada adalah "Mengembangkan Jaringan Kerja Sama Ekonomi dengan BUMDes yang lain maupun berbagai Pihak". Maka dari itu, perlu dilakukan kerja sama dengan pihak yang lebih luas sehingga dibutuhkannya Media penghubung antara BUMDes Katon Margo Sembada dengan pihak-pihak yang lain. Dari kegiatan pengabdian yang telah terlaksana dapat diambil kesimpulan sebagai berikut :

1. FGD (Focus Group Discussion) dapat terlaksana dengan baik dan lancar. FGD bertujuan untuk penilaian awal (initial assessment) permasalahan. Seperti apa saja kekurangan, potensi, dan hambatan yang berada di BUMDes Katon Margo Sembada

2. Penjualan produk secara digital marketing dapat digunakan untuk menjembatani para pihak BUMdes dimasa pandemi supaya tetap dapat pemasukan melalui pemasaran E-commerce.

3. Memberikan kesempatan kepada untuk melakukan pelatihan bersama dengan mengagendakan pertemuan bersama untuk berdiskusi dalam satu forum membahas tentang Workshop tata kelola media sosial dan website, pelatihan digital marketing dan pelatihan jurnalistik.

4. Terjalinnya kerja sama dengan mitra strategis BUMDes bekerja sama dengan Laboratorium Ilmu Pemerintahan Universitas Muhammadiyah Yogyakarta dalam pelaksanaan pengelolaan dan pendampingan berbasis teknologi informasi dan komunikasi

\section{DAFTAR PUSTAKA}

ANTARA. (2020). Penyebab 10.026 BUMDes Mampu Bertahan saat Pandemi Covid-19 . Nasional Tempo.co. https://nasional.tempo.co/read/136 7196/penyebab-10-026-bumdesmampu-bertahan-saat-pandemicovid-19

Badri, M. (2016). Pembangunan Pedesaan Berbasis Teknologi Informasi dan Komunikasi (Studi pada Gerakan Desa Membangun). Jurnal Dakwah Risalah, 27(2), 62-73. https://doi.org/10.24014/JDR.V27I 2.2514

Handajani, L., Abidin, Z., \& Pituringsih, E. (2021). Pendampingan Perintisan Usaha BUMDes untuk Pemberdayaan Ekonomi Masyarakat Desa Peteluan Indah. Abdi Insani, 8(1), 10-17. https://doi.org/10.29303/ABDIINS ANI.V8I1.362

Hartoyo, Maharani, N., \& Ika Merdekawati. (2016). Citalinuabdi: Upaya Membangun Sistem Informasi Desa Yang Bermakna. Jurnal Komunikasi Ikatan Sarjana Komunikasi Indonesia, 1(1), 48-57. http://www.jurnaliski.or.id/index.php/jkiski/article/vi ew/35

Undang-Undang Republik Indonesia Nomor 6 Tahun 2014 Tentang Desa, bphn.go.id http://www.bphn.go.id/data/docum ents/14uu006.pdf

JDIH BPK RI. (2013). PERDA Kab. Sleman No. 3 Tabun 2013 tentang Tata Cara Pembentukan dan Pengelolaan Badan Usaha Milike Desa. https://peraturan.bpk.go.id/Home/ Details/14983

Peraturan Menteri Desa, Pembangunan Daerah Tertinggal, dan Transmigrasi Nomor 4 Tabun 2015 Tentang Pendirian, 
Pengurusan Dan Pengelolaan, Dan Pembubaran Badan Usaha Milik Desa, (2015) (testimony of JDIH KEMENDESA).

http://jdih.kemendesa.go.id/katalog /peraturan_menteri_desa_pembangu nan_daerah_tertinggal_dan_transmig rasi_nomor_4_tahun_2015

Karinda, T., Waworundeng, W., \& Kimbal, A. (2020). Tata Kelola Badan Usahan Milik Desa (BUMDes). JURNAL POLITICO, 9(3). https://ejournal.unsrat.ac.id/index.p $\mathrm{hp} /$ politico/article/view/32097

Korten, D. (2002). Menuju Abad ke-21: Tindakan Sukarela dan Agenda Global. Yayasan Obor Indonesia.

Rosyada, A., Zainuddin, A., Andriyani, S., \& Wibowo, P. A. (2019). Pendampingan Pembentukan Badan Usaha Milik Desa (BUMDes) Desa Kendalasem Wedung Demak. Dinamisia: Jurnal Pengabdian Kepada Masyarakat, 3(2), 235-243. https://doi.org/10.31849/DINAMI SIA.V3I2.3292 